\title{
MICRO-MECHANICAL BEHAVIOR STUDY OF NON-METALLIC INCLUSIONS IN P/M DISK SUPERALLOY RENE'95
}

\author{
Xishan Xie ${ }^{1}$, Lina Zhang ${ }^{1,2}$, Maicang Zhang ${ }^{1}$, Jianxin Dong ${ }^{1}$, Kenneth Bain ${ }^{3}$ \\ ${ }^{1}$ High Temperature Materials Research Laboratories, University of Science \& Technology Beijing, Beijing 100083, China \\ ${ }^{2}$ Electron Microscopy Laboratory, School of Materials Science and Engineering, Tsinghua University, Beijing 100084, China \\ ${ }^{3}$ GE Aircraft Engines, Cincinnati, Ohio 45215, USA
}

Keywords: P/M Superalloy Rene'95, Non-metallic Inclusion, Micro-mechanical Behavior

\begin{abstract}
Specially designed SEM in-situ tensile and fatigue tests have been conducted to trace the entire process of crack initiation and propagation till fracture in $\mathrm{Al}_{2} \mathrm{O}_{3}$ seeded $\mathrm{P} / \mathrm{M}$ Rene'95 superalloy. Special thin foil TEM samples (with inclusions) were carefully prepared and detail observations were conducted with electron microscopy. The distribution of stress and strain field around inclusions has been calculated by means of an elasto-plastic finite element method (FEM) model with the commercial software, ANSYS. The results of this work are helpful to establish the practical life prediction model for the characteristic inclusion parameters in $\mathrm{P} / \mathrm{M}$ superalloy components.
\end{abstract}

\section{Introduction}

The mechanical properties, especially low cycle fatigue properties (LCF), of P/M superalloys have been seriously degraded by the existence of non-metallic inclusions which are introduced into the alloy during powder metallurgy processing [1-7]. From the 1980's, extrinsic ceramic inclusions have been studied, and many research programs have been done to investigate this problem. The work includes inclusion characterization and the effect of inclusions on mechanical properties especially LCF ability. According to these investigations, the main compositions of ceramic inclusions are $\mathrm{Al}, \mathrm{Si}, \mathrm{Ca}, \mathrm{Mg}$, and $\mathrm{Zr}$, and the typical inclusions are $\mathrm{Al}_{2} \mathrm{O}_{3}$ and $\mathrm{SiO}_{2}$. The size range of defects is from several nanometers to several hundred micrometers. Extrinsic inclusions act as origins for fatigue cracks, and decrease tensile properties and LCF capability of P/M superalloys. Numerous experimental results show that the LCF life of a P/M superalloy is closely related to the size, location and number of inclusions. The inclusion composition or type sometimes is not a significant factor. When the inclusion is at surface of component (or specimen), it is easier to form a fatigue crack initiation than if it is internal. With the increase of inclusion size for both surface and internal inclusions, the LCF life of P/M superalloy decreases. Many methods have been investigated to cope with inclusion problem [8]. These methods may be divided into two kinds by purpose. One is to diminish inclusion amount, while the other is to decrease inclusion size. However, getting completely clean superalloy is not currently possible. In order to assure the safety of $\mathrm{P} / \mathrm{M}$ superalloy components, it becomes imperative to accurately predict the LCF life of P/M superalloy with extrinsic inclusions [9, 10]. So the detail information of inclusions must be learned, especially the inclusion behavior during loading process. Up to date, only a few of publications have been studied on the micromechanical behavior of inclusions in $\mathrm{P} / \mathrm{M}$ superalloy and few systematical investigations or tests have been carried out.
In this paper, micro-mechanical behavior, such as crack initiation and propagation, of ceramic inclusions in P/M superalloy Rene'95 has been investigated.

\section{Experimental Materials \& Methods}

For expediently understanding the inclusion effect on crack initiation and propagation at different stress conditions, GE Aircraft Engines prepared the special P/M Rene'95 experimental material doped with alumina $\left(\mathrm{Al}_{2} \mathrm{O}_{3}\right)$ seeds. Fine powders $(-270$ mesh) of Rene'95 alloy and $\mathrm{Al}_{2} \mathrm{O}_{3}$ particles were mixed and processed by routine $\mathrm{P} / \mathrm{M}$ Rene'95 disk production. SEM in situ tension and fatigue tests and tracking observations were conducted in this project to directly monitor inclusion behavior at tension and fatigue stress conditions.

A careful specimen preparation was conducted. The flat tension and fatigue specimens with dimension $36 \times 10 \times 0.5 \mathrm{~mm}$ (see Fig.1) including the observed inclusions were selectively cut from the test materials. These inclusions must be located at the surface in the gauge length section of specimens. Each sample was mechanically polished and immersion etched for SEM observation.

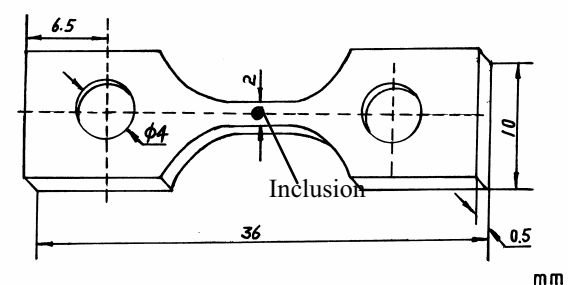

Fig.1 Schematic of SEM in-situ test specimen

SEM in-situ tension tests were conducted on the tensile loading stage in the chamber of SEM equipment which can control the load and displacement at ambient temperature. Similar with insitu tension tests, LCF in-situ tests were conducted on the fatigue loading stage in the chamber of SEM, which can control the cyclic stress and number of cycles at ambient temperature. The cyclic loading is in sine wave form. For micro-scale analyses on inclusion/matrix interfaces, deformation characteristics, dislocation configurations and micro cracking behaviors, special thin foil TEM samples (with inclusions) were carefully prepared and detail observations were conducted with TEM. Furthermore, stress and strain distribution around the simplified inclusions under tensile load has been calculated using the commercial finite element method (FEM) software ANSYS to augment the tests results. 


\section{Results and Discussion}

P/M Rene'95 alloy for this investigation has a nominal chemical composition (in wt \%) of $0.065 \mathrm{C}, 13 \mathrm{Cr}, 8 \mathrm{Co}, 3.5 \mathrm{Al}, 2.5 \mathrm{Ti}, 3.5 \mathrm{Nb}$, $3.5 \mathrm{Mo}, 3.5 \mathrm{~W}$, and balanced $\mathrm{Ni}$ and has been characterized as fine grain size ASTM 8 to 10 . The primary $\gamma^{\prime}\left(\mathrm{Ni}_{3}(\mathrm{Al}, \mathrm{Ti}, \mathrm{Nb})\right)$ of $1 \sim 5 \mu \mathrm{m}$ in diameter mainly locates at grain boundaries as shown in Fig.2. Secondary $\gamma^{\prime}(\sim 0.1 \mu \mathrm{m})$ and tertiary $\gamma^{\prime}$ precipitates are very fine and dispersively distribute in grains (see Fig.3). A few MC $(\mathrm{NbC})$ carbide particles randomly distribute at grain boundaries and in the grains both.

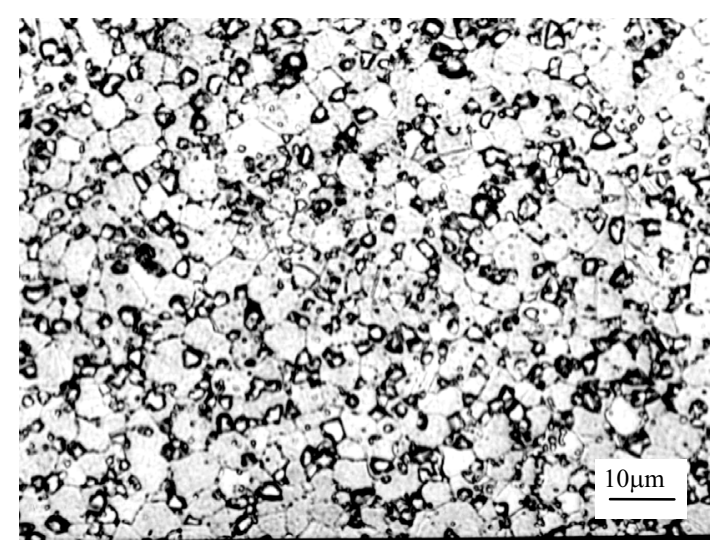

Fig.2 OPM structure of P/M Rene'95

The white blocky particles indicate primary $\gamma^{\prime}$

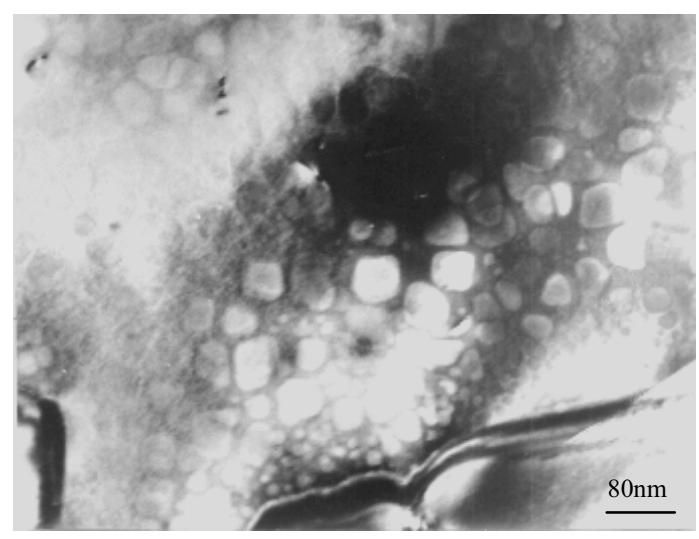

Fig.3 TEM structure of precipitated $\gamma^{\prime}$ particles

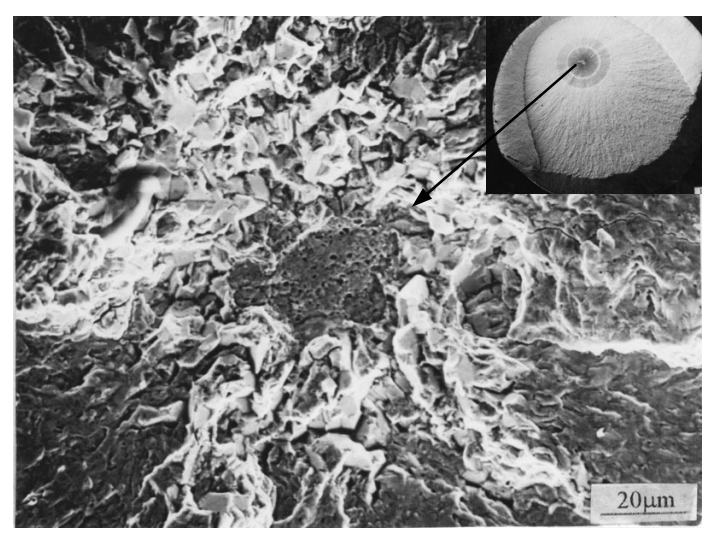

Fig.4 SEM fractography of a commercial P/M Rene'95 LCF failed sample
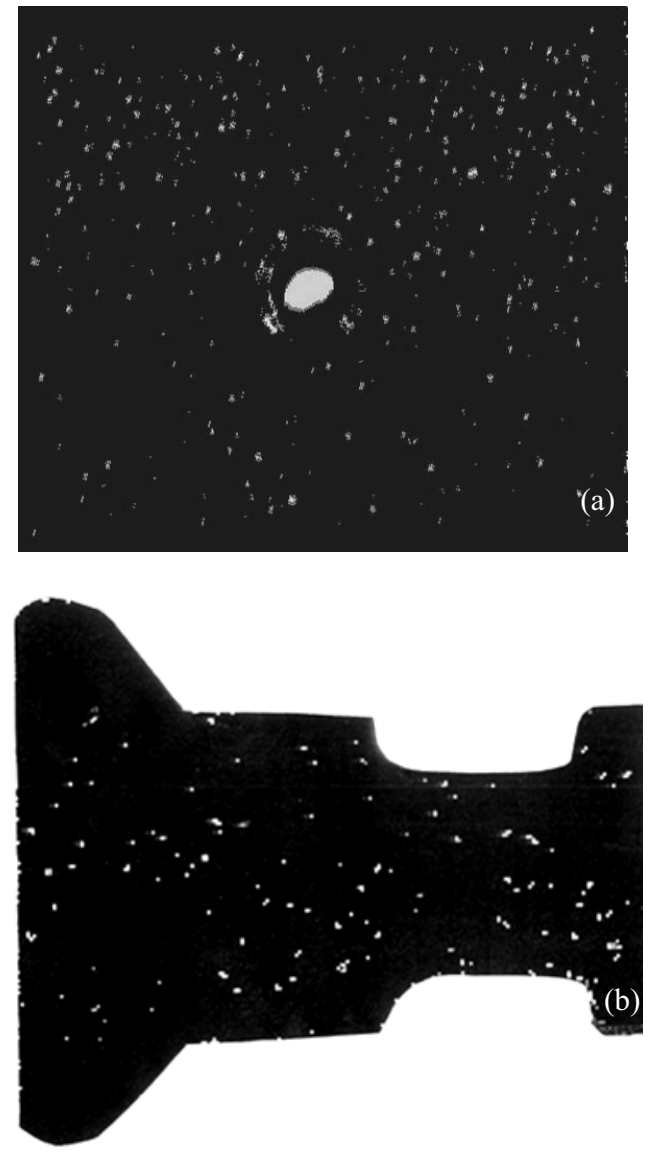

Fig.5 Inclusion distribution image of P/M Rene'95 detected by ultrasonicNDT (white spots indicate inclusions $\geq 50 \mu \mathrm{m}$ )

(a) P/M Rene' 95 sample block $(40 \times 50 \times 5 \mathrm{~mm})$

(b) a section of $\mathrm{P} / \mathrm{M}$ Rene' 95 experimental disk

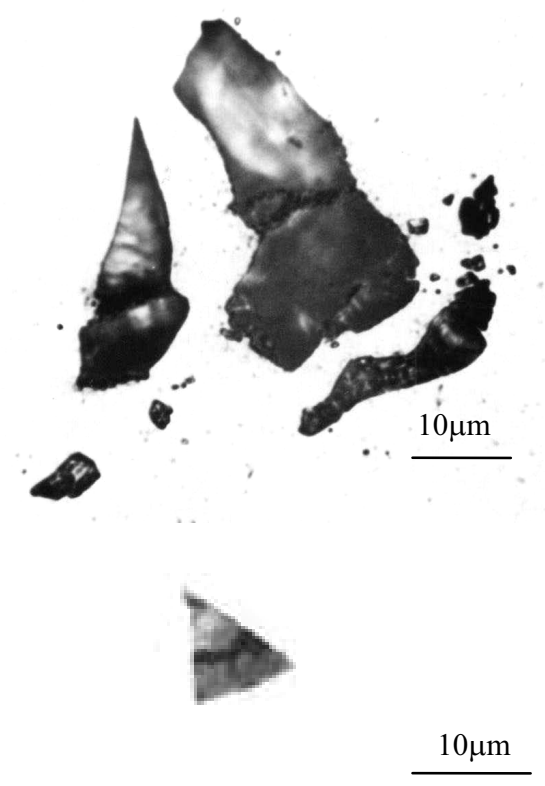

Fig.6 OPM morphology of $\mathrm{Al}_{2} \mathrm{O}_{3}$ inclusions with different sizes (polished surface of sample) 
LCF test results show that nonmetallic inclusions were the origins of fatigue cracks in PM Rene'95. Fig.4 shows SEM fractography of a commercial P/M Rene'95 sample after LCF test to failure. The fracture was initiated at a piece of nonmetallic inclusion as shown by the arrow in Fig.4. Fig. 5 shows the distribution image of inclusions in a sample block and an experimental disk doped by $\mathrm{Al}_{2} \mathrm{O}_{3}$ seeds. Fig.6 illustrates optical microscopy morphology of $\mathrm{Al}_{2} \mathrm{O}_{3}$ inclusions with different sizes in the investigated material. Some of them are composed of several pieces, which were broken down from one inclusion particle during manufacturing process. The interfaces of inclusions/matrix are just mechanically contacted but not metallurgically bonded. There is no transition zone between matrix and inclusions.

\section{$\underline{\text { SEM In-situ Tension Observation }}$}

Surface Inclusion. According to the results of the SEM in-situ tension observation, the cracks can initiate at ceramic inclusion, and the effect of inclusions with different sizes on cracking behaviors is different.

Figure 7 shows the results of in-situ tensile test specimen with a small $\mathrm{Al}_{2} \mathrm{O}_{3}$ inclusion. A triangular $\mathrm{Al}_{2} \mathrm{O}_{3}$ particle about $10 \mu \mathrm{m}$ in size is shown in Fig.7a before loading. The loading direction is horizontal as shown by the arrows. The morphology of inclusion or matrix has no change until the tensile stress is up to the yield strength $\left(\sigma_{\mathrm{s}}\right)$ level. Fig. $7 \mathrm{~b}$ illustrates the morphology of inclusion and matrix after the yielding of alloy. There are slip bands throughout matrix and the surface of the specimen becomes scraggly. With the increasing of the load, sliding deformation becomes severe and a cracking occurs in the inclusion (as arrow indicated in Fig.7c). The crack widens continuously with the increase in stress until the specimen fails and the small triangle inclusion is divided into two pieces (Fig.7d).

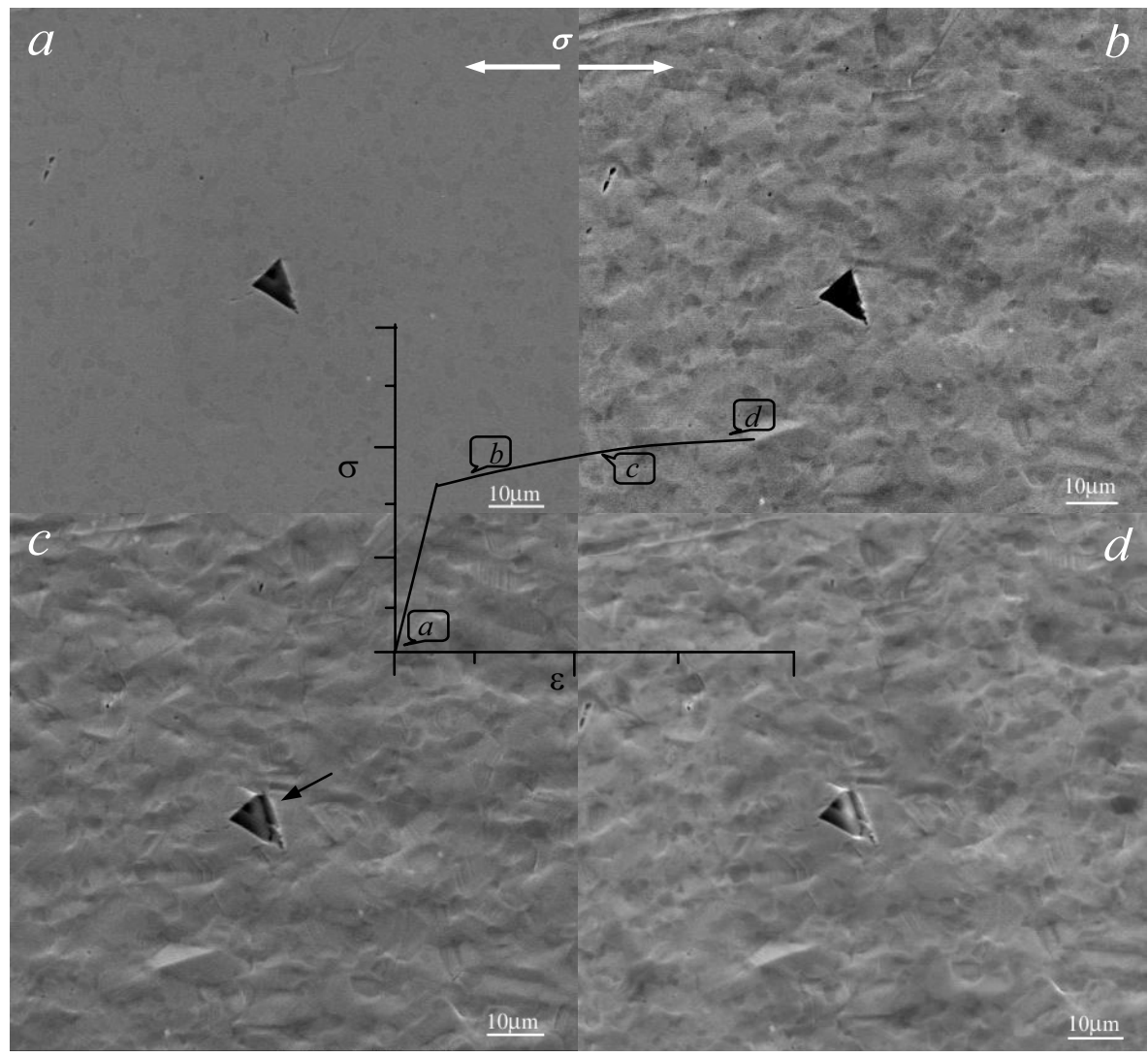

Fig.7 A small triangular inclusion behavior during SEM in-situ tension process (a) before loading (d) after specimen fracture

Figure 8 shows the results of an in-situ tensile test of a specimen with a relatively large ceramic $\mathrm{Al}_{2} \mathrm{O}_{3}$ inclusion, which is about 50 $\mu \mathrm{m}$ in maximal length. This inclusion has been broken into several pieces during material processing before loading as shown in Fig.8a. After loading, at the stress level even lower than yield (point b), it is different from the small inclusion behavior as shown in Fig.7. Cracks initiate at the inclusion/matrix interfaces as shown in Fig.8b. This occurs at stress levels lower than the yield stress. The sliding deformation in the matrix has not happened. It can be seen that a small crack also initiates at one of the left corner of the inclusion. At this moment, the matrix does not deform and the load is about $0.8 \sigma_{\mathrm{s}}$ of the matrix. It shows that the cracks initiate at the inclusion/matrix interface before matrix yielding. With increasing of external tension loading, the initiated cracks at the inclusion/matrix interface widen. The cracks join each other and propagate into matrix (Fig.8c). The inclusion can be separated from the matrix and the deformation of matrix becomes obvious. As the specimen fails, the cracks become wider, and some pieces of the inclusion have already fallen out from matrix (Fig.8d).

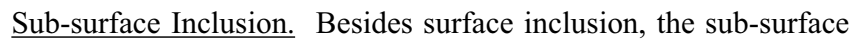
inclusion (inclusion near to the surface) is also significant. Figure 9 shows a pair of matching fracture surfaces of P/M Rene' 95 with inclusions after in-situ tensile loading test to failure. The crack 


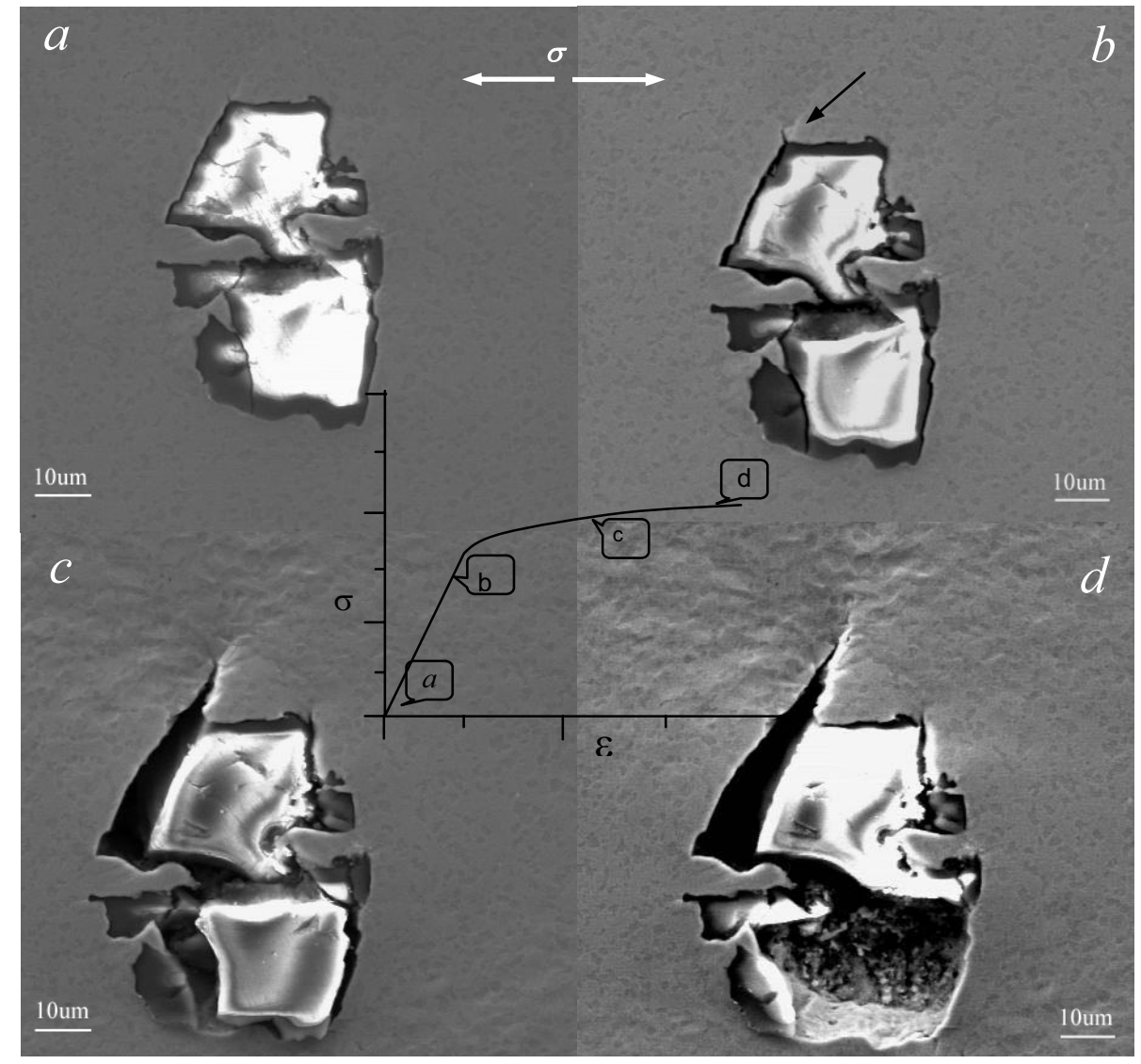

Fig.8 SEM in-situ tension observation of a larger $\mathrm{Al}_{2} \mathrm{O}_{3}$ inclusion in $\mathrm{P} / \mathrm{M}$ Rene'95. (a) before loading (d) after specimen fracture

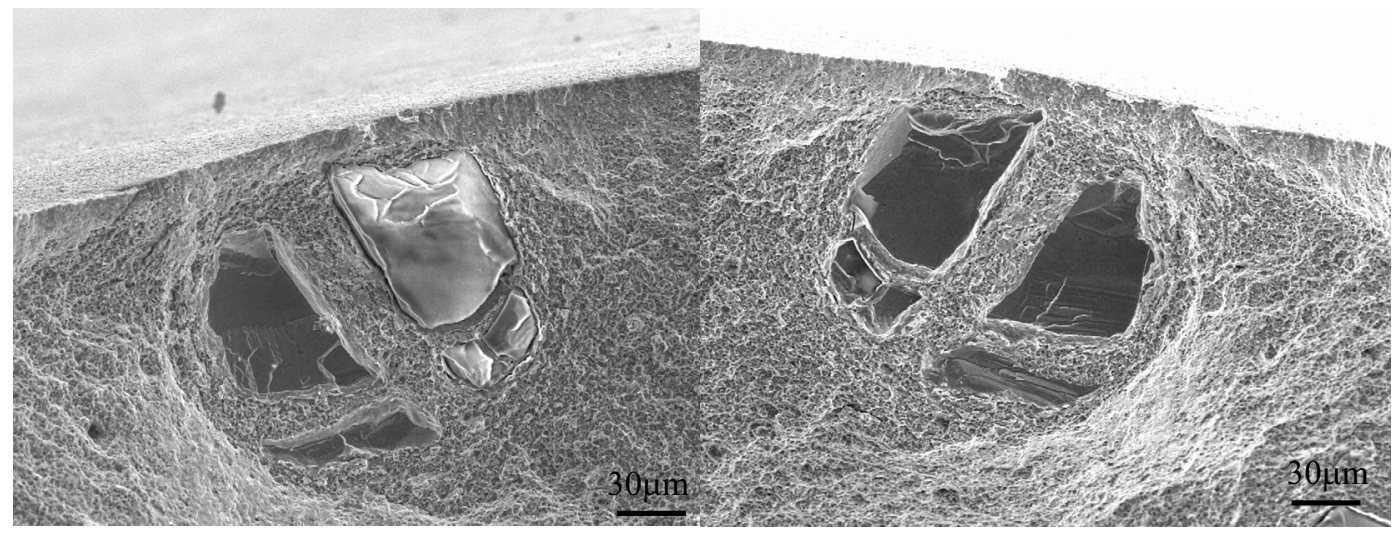

Fig.9 A pair of matching fracture surface with inclusions near to the sample surface

origin is a cluster of $\mathrm{Al}_{2} \mathrm{O}_{3}$ inclusion near to the surface, but not the surface inclusion. It shows that when the inclusion near to the surface is bigger than the surface one, the former is still the crack initiation site. Failure occurs from the big sub-surface inclusion but not from the smaller surface inclusion.

The results of the SEM in-situ tension observation reveal that the effects of inclusions with different sizes on the cracking behavior are different in two aspects. First, for the small triangular $\mathrm{Al}_{2} \mathrm{O}_{3}$ particle (about $10 \mu \mathrm{m}$ ), the crack occurs after sample yielding, while the crack initiates at the bigger inclusion (about $50 \mu \mathrm{m}$ ) before matrix yielding. Second, the cracks initiate at different locations. For the small inclusions, the crack usually forms in the inclusion. For the bigger Inclusion, the crack initiates at the inclusion/matrix interface easily. This is why the inclusion with big size is more detrimental to mechanical properties of $\mathrm{P} / \mathrm{M}$ Rene'95.

\section{$\underline{\text { SEM In-situ Fatigue Observation }}$}

SEM in-situ fatigue tests with stresses of sine wave form and different amplitudes were conducted in a stress ratio of 0.1 (ie. $\mathrm{R}=0.1$ ). 
Fig. 10 shows the in-situ fatigue observation on a surface $\mathrm{Al}_{2} \mathrm{O}_{3}$ inclusion with $\sigma_{\max }=1000 \mathrm{MPa}$. The inclusion size is about $60 \times 70$ $\mu \mathrm{m}^{2}$. The initial morphology of this inclusion in matrix is shown in Fig.10a. At $\mathrm{N}=5000$ cycles, the crack at inclusion/matrix interface began to grow. After $\mathrm{N}=6000$ cycles, the crack propagated rapidly. When $\mathrm{N}=7000$ cycles, the specimen failed. Fig. 10(c) and $\left(c^{\prime}\right)$ are the matched fracture surfaces from two failed parts of a specimen.

Fig.11 displays the result of in-situ fatigue observation on $\mathrm{P} / \mathrm{M}$ Rene' 95 with a surface inclusion cluster when maximum stress is $600 \mathrm{MPa}$. The loading direction is shown by black arrows. Fig.11a shows the original morphology of an inclusion before cyclic loading. This inclusion is about $60 \mu \mathrm{m}$ in size. There are two small

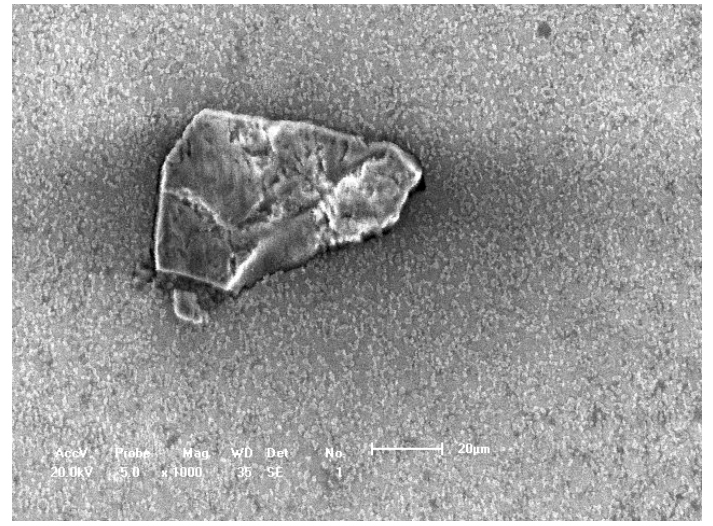

(a) $\mathrm{N}=0$

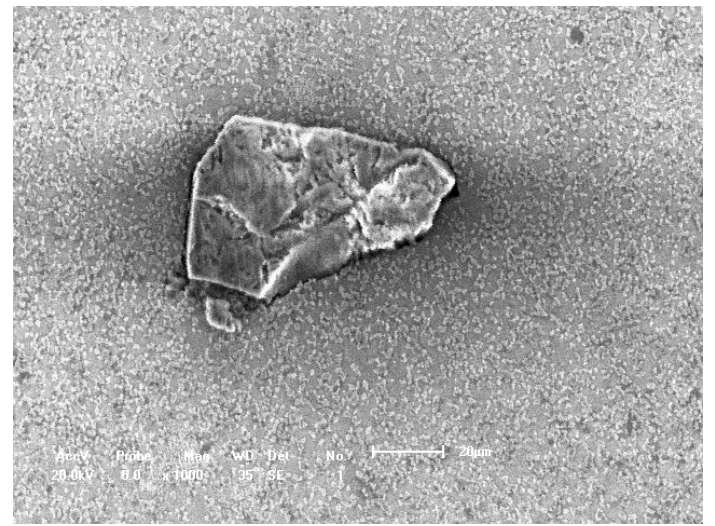

(b) $\mathrm{N}=5000$ inclusion particles near the right corner of the big inclusion. With increasing fatigue cycles, an interface of the inclusion/matrix is separated and a small crack occurs (see Fig.11b). Initial cracks at the interfaces of big inclusion/matrix and small inclusion/matrix (see Fig.11c) widen continuously, and at cycle number $\mathrm{N}=116316$, two cracks connected together through the matrix between big and small inclusions. The deformation of matrix around inclusions is so intense that a part of the big inclusion particle has been pulled out from the matrix (as shown in Fig.11d). The connected large crack grows into the matrix step by step from both sides of the big $\mathrm{Al}_{2} \mathrm{O}_{3}$ particle. When $\mathrm{N}=158209$ cycles, the crack propagates rapidly until failure. A piece of big inclusion particle still remains in the matrix as shown in Fig.11f.

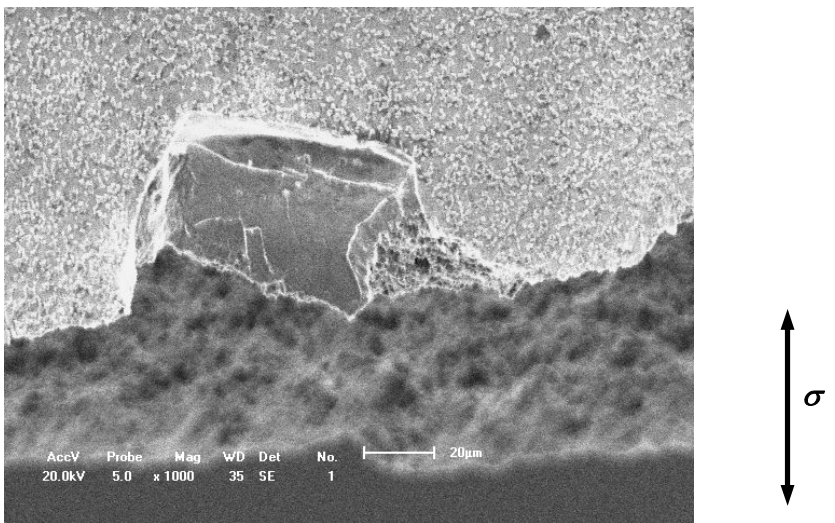

(c) $\mathrm{N}=7000$

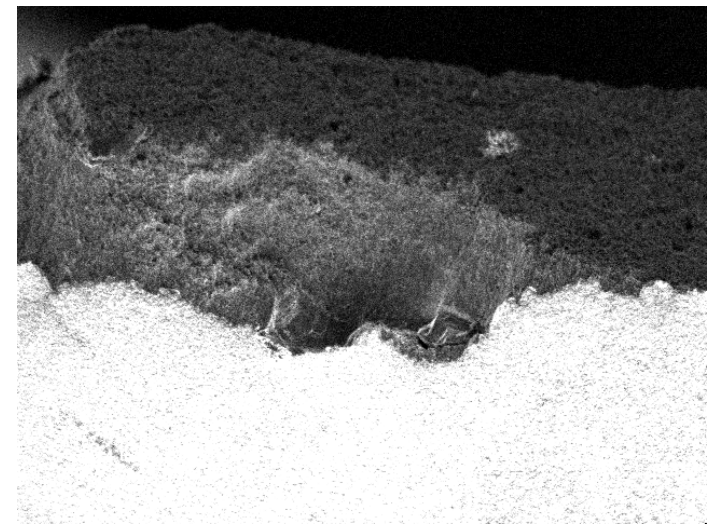

$\left(c^{\prime}\right) \mathrm{N}=7000$

Fig.10 Inclusion behavior during SEM in-situ fatigue test $(\sigma=1000 \mathrm{MPa}, \mathrm{R}=0.1)$

The experimental results show that inclusions will easily initiate fatigue cracks even when the stress level is far lower than the yield stress of P/M Rene'95. When the LCF stress is higher, the fatigue crack initiates earlier at inclusions.

\section{$\underline{\text { TEM Observation }}$}

SEM in-situ tension and fatigue tests indicate that cracks tend to form at ceramic inclusions due to the local stress concentration. Fig. 12 represents the dislocation configuration near a very small inclusion. It implies that a stress concentration existed at the inclusion/matrix interface before loading. The stress concentration could be induced during the $\mathrm{P} / \mathrm{M}$ material manufacturing process. Fig. 13 shows a relative large ceramic inclusion. The dislocation concentration and even a small crack can be observed inside the inclusion particle. Under loading, the existing stress concentration becomes intense and the micro-cracks (voids) at inclusion/matrix interface or in the inclusion can develop or expand. When the stress is higher than the yield stress, the cracks will form at inclusion/matrix interface or in the inclusion.

When the inclusion size is very small, the crack initiation in PM Rene'95 can also happen at the interfaces of primary $\gamma^{\prime}$ /matrix. Fig. 14 shows the TEM image of dislocation concentrations around primary $\gamma^{\prime}$ particle. SEM in-situ tension test specimens without surface inclusions indicate that the crack initiates at primary $\gamma^{\prime} /$ matrix interfaces and propagates into a long crack (Fig.15).

TEM of an in-situ tension test was conducted and the results suggest that the crack can grow along primary $\gamma^{\prime}$ particles. Fig.16 


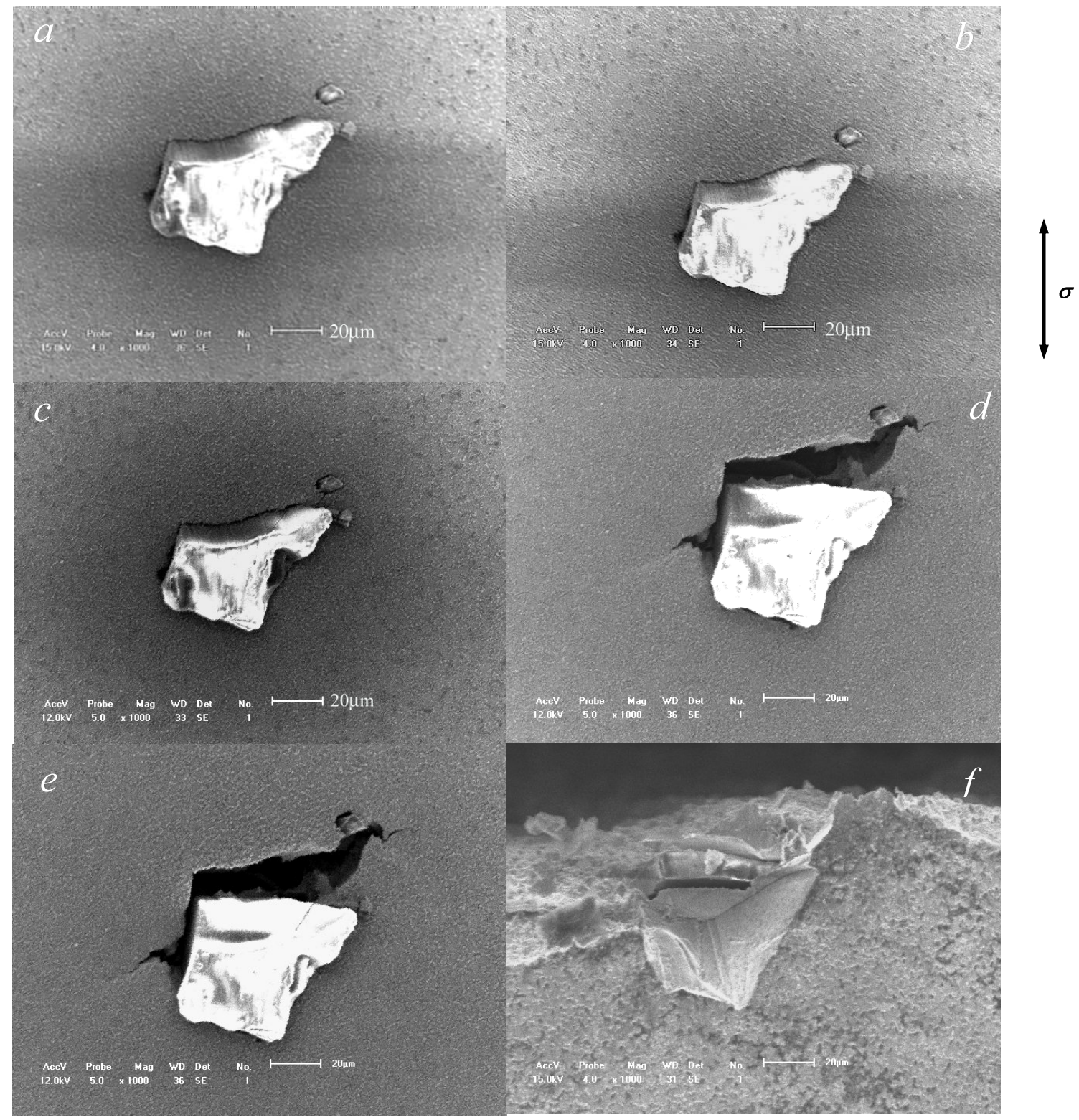

Fig.11 Inclusion behavior during SEM in-situ fatigue test $\left(\sigma_{\max }=600 \mathrm{MPa}\right)$

(a) $\mathrm{N}=0$, (b) $\mathrm{N}=2068$, (c) $\mathrm{N}=101335$, (d) $\mathrm{N}=116316$ (e) $\mathrm{N}=158116$, (f) $\mathrm{N}=158209$

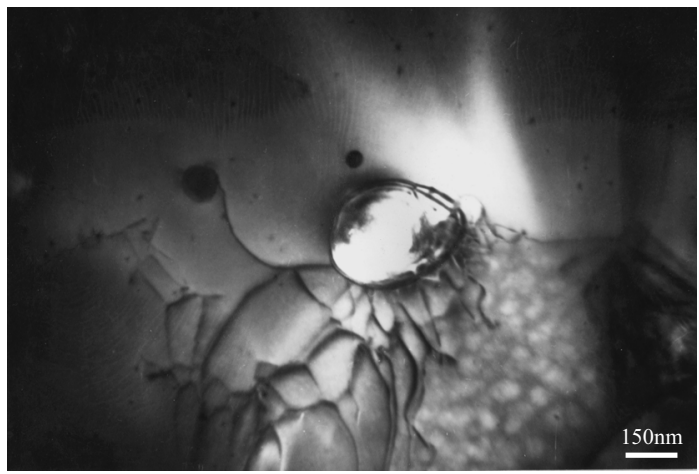

Fig.12 TEM observation of a very small $\mathrm{ZrO}-\mathrm{Al}_{2} \mathrm{O}_{3}$ inclusion particle illustrates a TEM of an in-situ tension test with a micro-crack changing its propagating orientation due to the existence of two large primary $\gamma^{\prime}$ particles.

\section{$\underline{\text { FEM Analysis }}$}

Finite element simulation of surface semispherical $\mathrm{Al}_{2} \mathrm{O}_{3}$ and $\mathrm{P} / \mathrm{M}$ Rene'95 matrix during tensile process was conducted to investigate the stress-strain field development around an inclusion particle. The inclusion size and loading process simulated that of the in-situ mechanical tests. Fig. 17 illustrates the simulation results. The tensile loading direction is along axis Z. From Fig. 17 (a)(b)(c), show the stress field at surface inclusion and matrix are at different stress levels. Calculation results show that stress concentrates at the pole area of the inclusion and its vicinity (as 


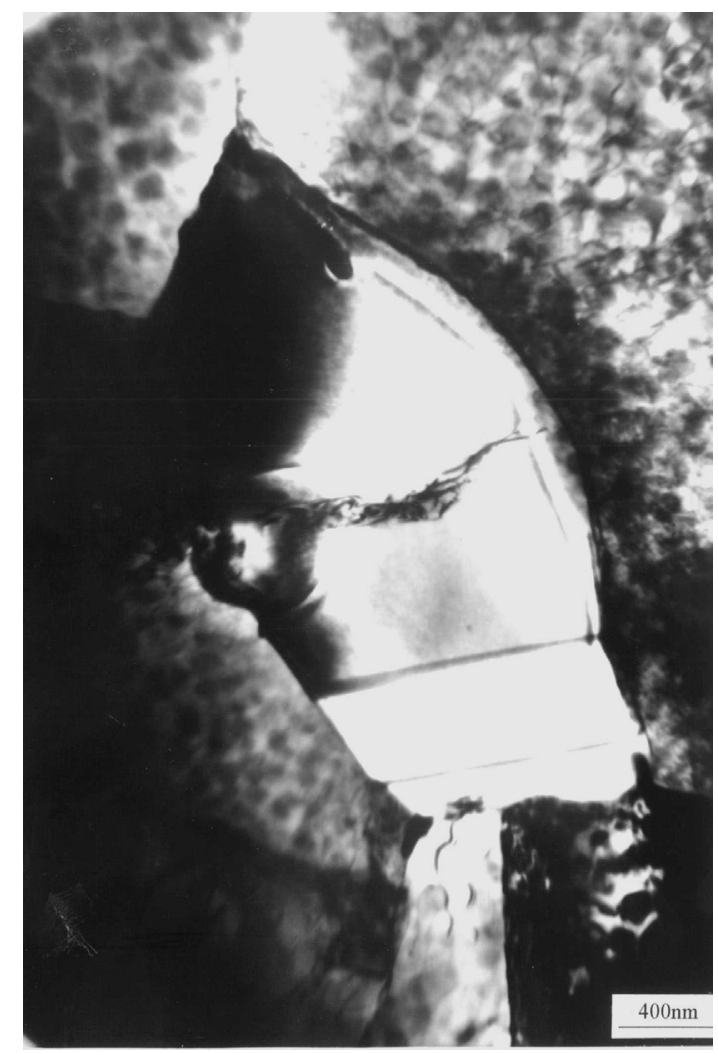

Fig.13 TEM image of a relative large $\mathrm{Al}_{2} \mathrm{O}_{3}$ particle of $\mathrm{P} / \mathrm{M}$ Rene' 95

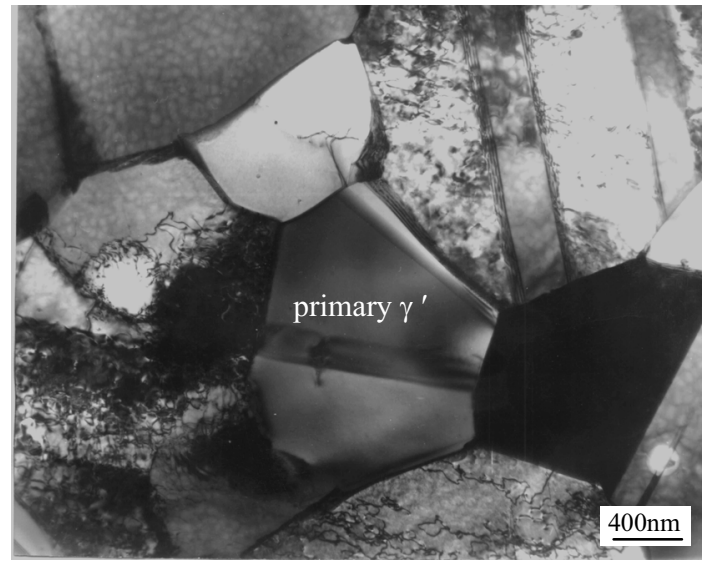

Fig.14 Dislocations around the primary $\gamma^{\prime}$ particle

shown by the arrow in Fig.17(a)). The stress reduces gradually from the pole of inclusion to equator face. During in-situ tension testing, surface inclusion/matrix interfaces are only mechanically bonded. Cracks can form by separating the interface of inclusion particle and matrix at a load about $0.8 \sigma_{s}$. Crack location will be at the pole area of the inclusion. The simulation results are in agreement with the in-situ tensile experiments. The stress concentration around the inclusion increases with increasing in tensile stress. When the tensile stress $\sigma$ reaches $1120 \mathrm{MPa}$, that is about $0.8 \sigma_{s}$ ( $\sigma_{s}$ is yielding strength of the alloy), local plastic deformation (see Fig.17 (c')) occurs in the matrix near the inclusion. If the interface strength is low, a crack can initiate at the inclusion/matrix interface.

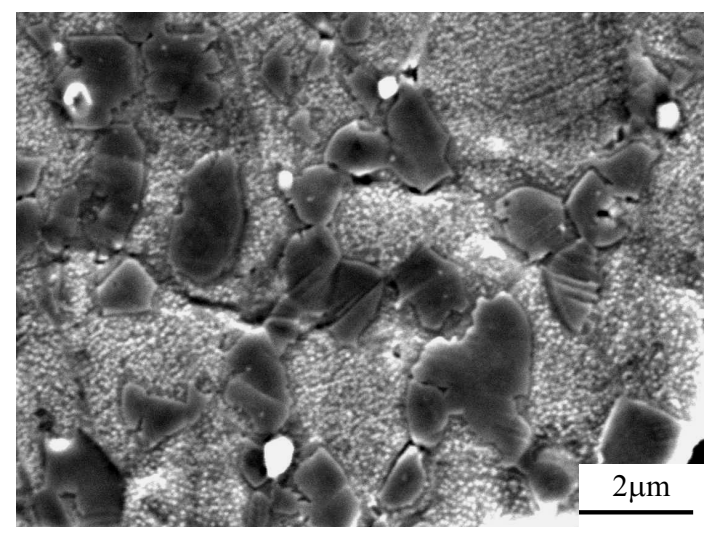

Fig. 15 Crack initiates at and propagates along primary $\gamma^{\prime}$ phase by SEM in-situ observation on specimen without surface inclusion

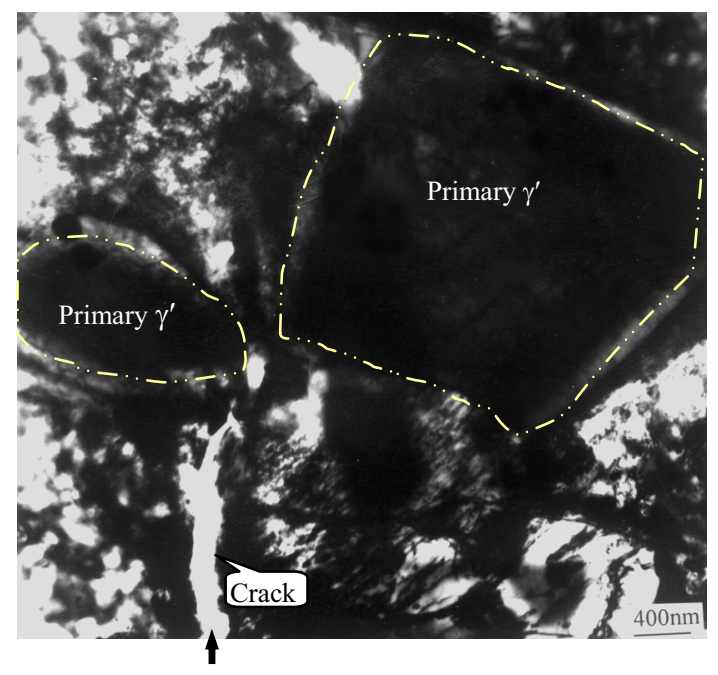

Fig.16 A micro-crack changes its growing orientation due to the existence of two primary $\gamma^{\prime}$ particles at TEM in-situ tension test

The results of this investigation can offer an experimental basis for physical and mechanical modeling for the life of P/M Rene'95 material in the presence of inclusions.

According to experimental results, it can be certainly found out that a critical inclusion size exists. When an inclusion is smaller than the critical size, the earliest crack may not initiate at the inclusion for the tensile stress level lower than yield stress. These small size inclusions may not be harmful to the mechanical properties such as tensile strength and LCF life. At this condition cracks may initiate at the interfaces of big primary $\gamma^{\prime} /$ matrix and propagate along the big primary $\gamma^{\prime}$. More detailed work should be done on the micro-mechanical behavior of inclusions in $\mathrm{P} / \mathrm{M}$ Rene'95 to gain a value of critical inclusion size for a reasonable life time prediction on the $\mathrm{P} / \mathrm{M}$ superalloy.

\section{Conclusions}

1. The inclusion behavior in alumina $\left(\mathrm{Al}_{2} \mathrm{O}_{3}\right)$ seeded $\mathrm{P} / \mathrm{M}$ Rene'95 superalloy has been investigated by SEM in-situ tension and fatigue tests. Direct observations of inclusion behavior reveals, that during the loading process, cracks initiate at the inclusion/ 

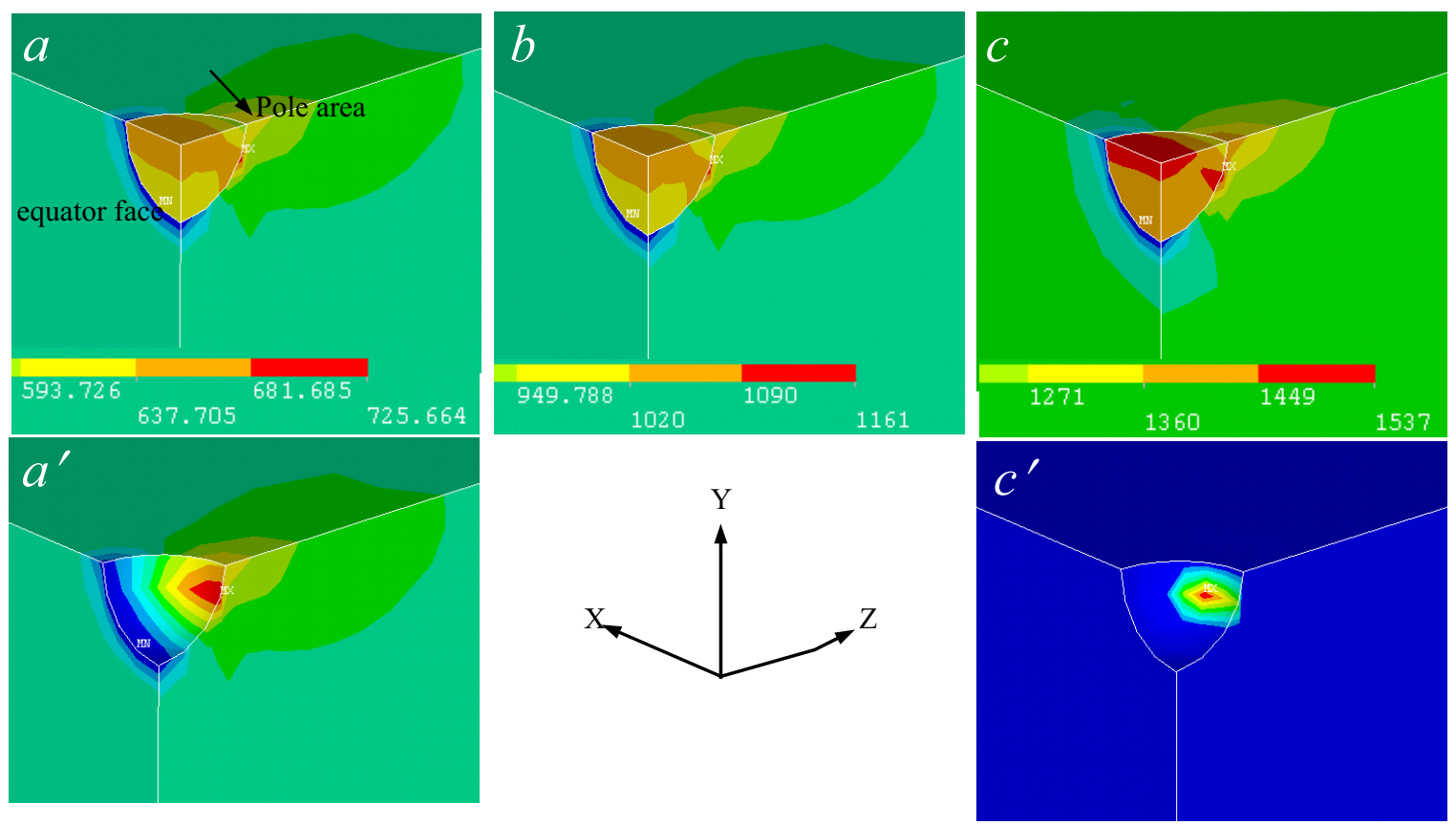

(a) $\sigma=500 \mathrm{MPa}$

(b) $\sigma=800 \mathrm{MPa}$

(a') Distribution of $1^{\text {st }}$ principle stress of matrix

(c) $\sigma=1120 \mathrm{MPa}$

Fig.17 Distribution of $1^{\text {st }}$ principle stress of simulated tensile process by means of FEM model on P/M Rene95 with surface inclusion

matrix interface, and may also initiate at sharp corners of inclusions. Cracks can propagate into the matrix for further stress release. The crack may also initiate inside the inclusion. The crack may propagate directly into or through the inclusion and the inclusion can be cut or broken into two or more pieces.

2. TEM observation reveals the dislocation configuration at the inclusions. When the dislocation arrays meet the inclusion (as a stable obstacle), they pile up to form stress concentration at the inclusion/matrix interface for crack initiation and propagation.

3. FEM simulation shows that a stress concentration occurs at the pole area of spherical inclusion under tensile loading. The stress concentration increases with load or inclusion size. Given an inclusion of a set size, local plastic deformation initially occurs at the matrix side of inclusion/matrix interface. This occurs at the stress level lower than the yield strength of Rene'95. The mismatch of deformation between inclusion and matrix leads to crack initiation and propagation at interface before the alloy matrix yields.

4. A critical inclusion size should exist according to SEM in-situ tests. A critical size of inclusion, which is harmful for mechanical properties (such as tensile and LCF), can be found by the further experimental and modeling investigation.

Acknowledgments: This project was supported by GE Aircraft Engines, Cincinnati, USA.

\section{References}

1. C. E. Shamblen et al, "Effect of Inclusions on LCF Life of HIP Plus Heat Treated Powder Metal Rene95", Metall. Trans. B , 168 (1985), 775-784.
2. Eric S. Huron, Paul G. Roth., "The Influence of Inclusion on Low Cycle Fatigue Life in a P/M Nickel-Base Disk Superalloy", (Paper presented at Symposium of Superalloy 1996), 359.

3. P. G. Roth et al., "Heavy Liquid Separation: a Reliable Method to Characterize Inclusions in Metal Powder," (Paper presented at conference of Advances in Powder Metallurgy and Particulate Materials, Canada, 1994), 112.

4. D. R. Chang et al., "Superalloy Powder Processing, Properties and Turbine Disk Applications," (Paper presented at meeting of Superalloys 1984), 245.

5. J. C. Lautridou et al, "Effect of Inclusions on LCF Life of PM Superalloys for Turboengine Discs," (Paper presented at conference of High Temperature Materials for Powder Engineer, 1990), Part II, 1163-1172.

6. J. M. Hyzak, I M Bernstein., "The Effect of Defects on the Fatigue Crack Initiation Process in Two P/M Superalloys, Part1, Fatigue Origins," Metall. Trans. A, 13 (1982), 33-43.

7. J. M. Hyzak, I. M. Bernstein. "The Effect of Defects on the Fatigue Crack Initiation Process in Two P/M Superalloys. Part2, Surface-subsurface Transition, Metall. Trans. A, 13(1982), 45-52.

8. T. S. Cockcrof et al., "Inclusions and the EB Refining of Superalloys.", (Paper presented at the meeting of Electron Beam Melting and Refining State of the Art, USA, 1992), 143.

9. J. Grison, L. Remy., "Fatigue Failure Probability in a Powder Metallurgy Ni-base Superalloy," Engineering Fracture Mechanics, 57(1997), 41-55.

10. A. Bruckner-Foit, H. Jackels, U. Quadfasel, "Prediction of the Lifetime Distribution of High-Strength Components Subjected to Fatigue Loading," Fatigue Fract. Engng Mater. Struct., 16(1993), 891-908. 